\title{
EXPLORING THE ORPHAN GPCR GPR18 THROUGH NOVEL SYNTHETIC CANNABIDIOL DERIVATIVES
}

Lago-Fernandez, A., ${ }^{1}$ Zhao, P., ${ }^{2}$ Sotudeh N., ${ }^{3}$ Leo, LM., ${ }^{2}$ Brailou, E., ${ }^{2}$ Hurst, DP., ${ }^{3}$ Morales, P., ${ }^{1}$ Reggio, PH., ${ }^{3}$ Abood, ME, ${ }^{2}$ and Jagerovic, N. ${ }^{1}$

IInstituto de Química Médica, Consejo Superior de Investigaciones Cientificas, Madrid, Spain ${ }^{2}$ Center for Substance Abuse Research, Temple University, Philadelphia, USA

\section{INTRODUCTION}

GPR18 is an orphan GPCR highly expressed in lymphoid tissues and the central nervous system that regulates cellular migration, proliferation, nociociception, and immunomodulation. The endocannabinoid derivative N-Arachidonoylglycine (NAGly) has been proposed as the putative endogenous ligand. Several other cannabinoids also interact with GPR18, such as Abn-CBD and $\triangle^{9}$-THC. However, very few potent synthetic GPR18 ligands have been described so far. A new family of compounds based on the cannabidiol scaffold were designed to target GPR18. Calcium mobilization imaging studies ${ }^{1}$ and docking studies in a in silico model ${ }^{2}$ were used to evaluate the activity of compounds and their mechanism of action, respectively. Here, two of the best compounds are exemplified: S5, a GPR18 agonist, and S4, a GPR18 antagonist.

\section{METHODS}

Synthesis. A new family of GPR18 ligands were synthesized following procedure exemplified in Scheme 1.

Calcium imaging. Intracellular calcium measurements were performed in hGPR18-CHO-K1 cells, following a procedure previously described by us ${ }^{1}$.

Docking. Global minimum energy conformers of each ligand were carried out with ab initio Hartree-Fock 6-31G* calculations with Spartan (Wave Function, Inc., Irvine CA) and manually docked into the receptor model previously published ${ }^{2}$.

\section{RESULTS}

Among the novel structures, $\mathbf{S} 4$ and $\mathbf{S 5}$ showed the best results in the pharmacological evaluation (Figure 1A-D). Docking studies revealed that the complex of $\mathbf{S 5}$ and the active state of the GPR18 is stabilized through H-bonds with $\operatorname{Arg}^{191}$ (R5.42) and Arg78 (R2.60), an aromatic H-bond with Y180 and aromatic stacking with Phe ${ }^{252}$ (F6.55) (Figure 2A). Meanwhile, the complex of S4 with the inactive state of GPR18 is stabilized by H-bond with $\operatorname{Arg}^{191}$ (R5.42), cation- $\pi$ interactions with Arg ${ }^{191}$ (R5.42) and Arg ${ }^{78}$ (R2.60) and aromatic stacking with Phe 248 (F6.51) and Phe 252 (F6.55) (Figure 2B).

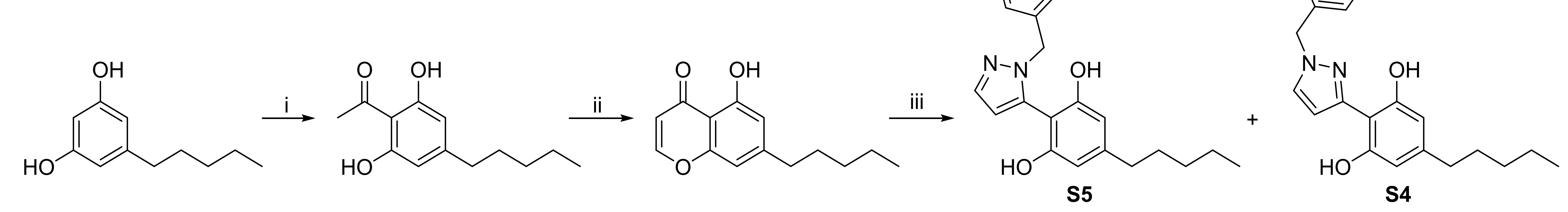

Scheme 1. i) $\mathrm{BF}_{3} \cdot \mathrm{Et}_{2} \mathrm{O}, \mathrm{AcOH}, 80^{\circ} \mathrm{C}, \mathrm{O} / \mathrm{N}(75 \%)$; ii) $\mathrm{BF}_{3} \cdot \mathrm{Et}_{2} \mathrm{O}, \mathrm{CH}_{3} \mathrm{SO}_{2} \mathrm{Cl}, 90^{\circ} \mathrm{C}, 4 \mathrm{~h}\left(86 \%\right.$ ); iii) $\mathrm{BzNHNH}_{2} \cdot 2 \mathrm{HCl}, \mathrm{EtOH}$, reflux, $3 \mathrm{~h},(\mathbf{S 5}: 85 \%$; S4: $14 \%)$.

$1 \mathrm{~A}$

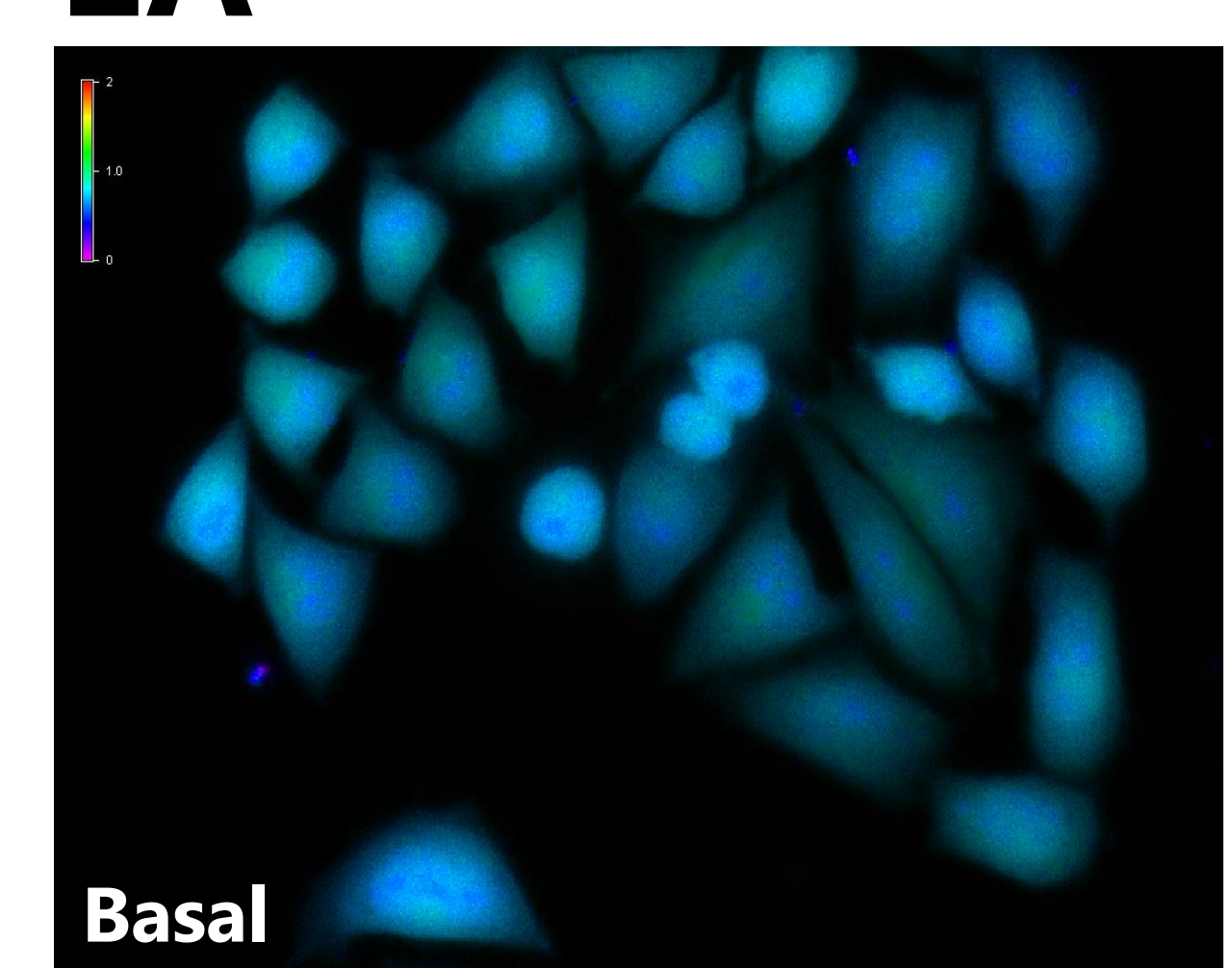

$1 \mathrm{C}$

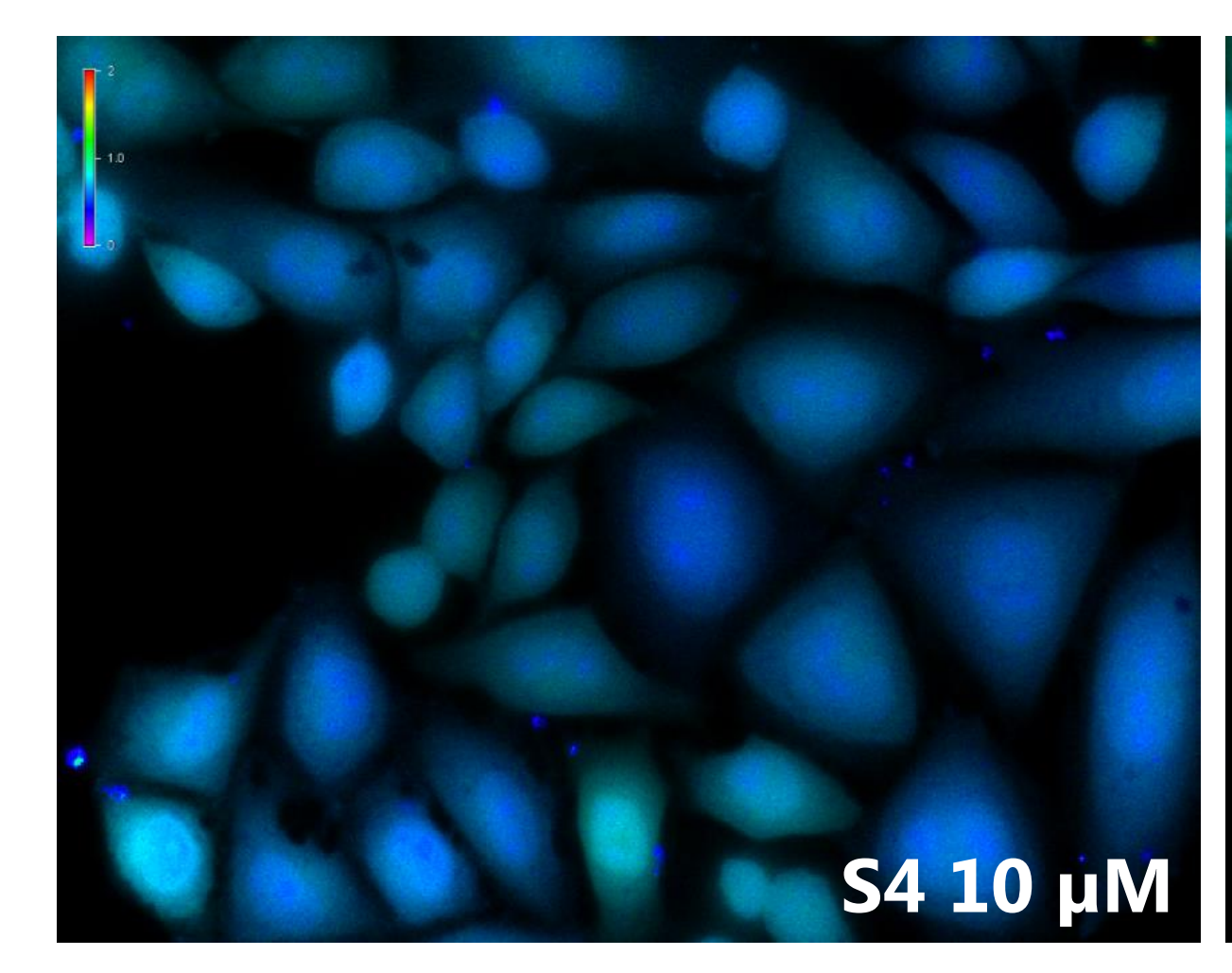

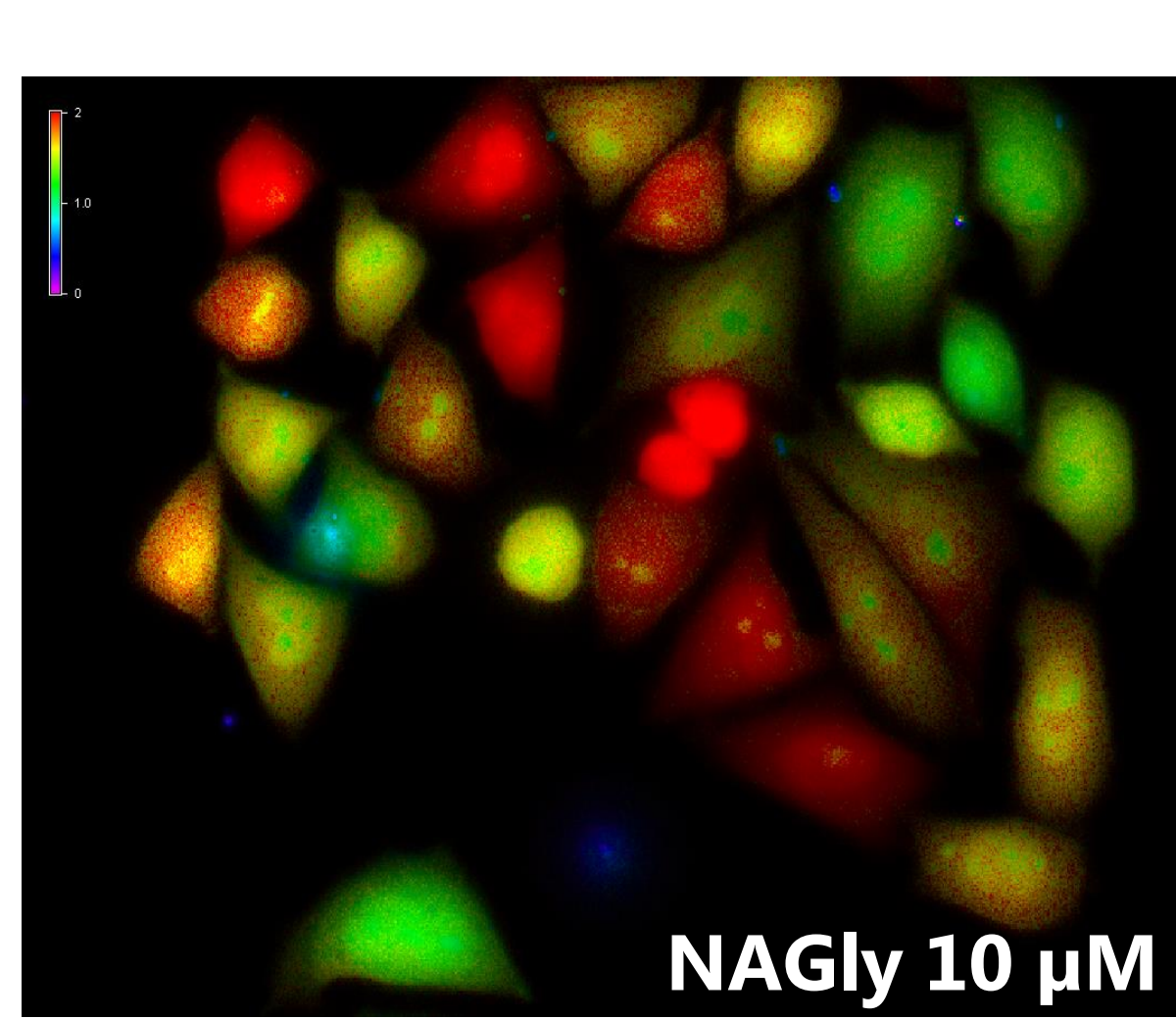

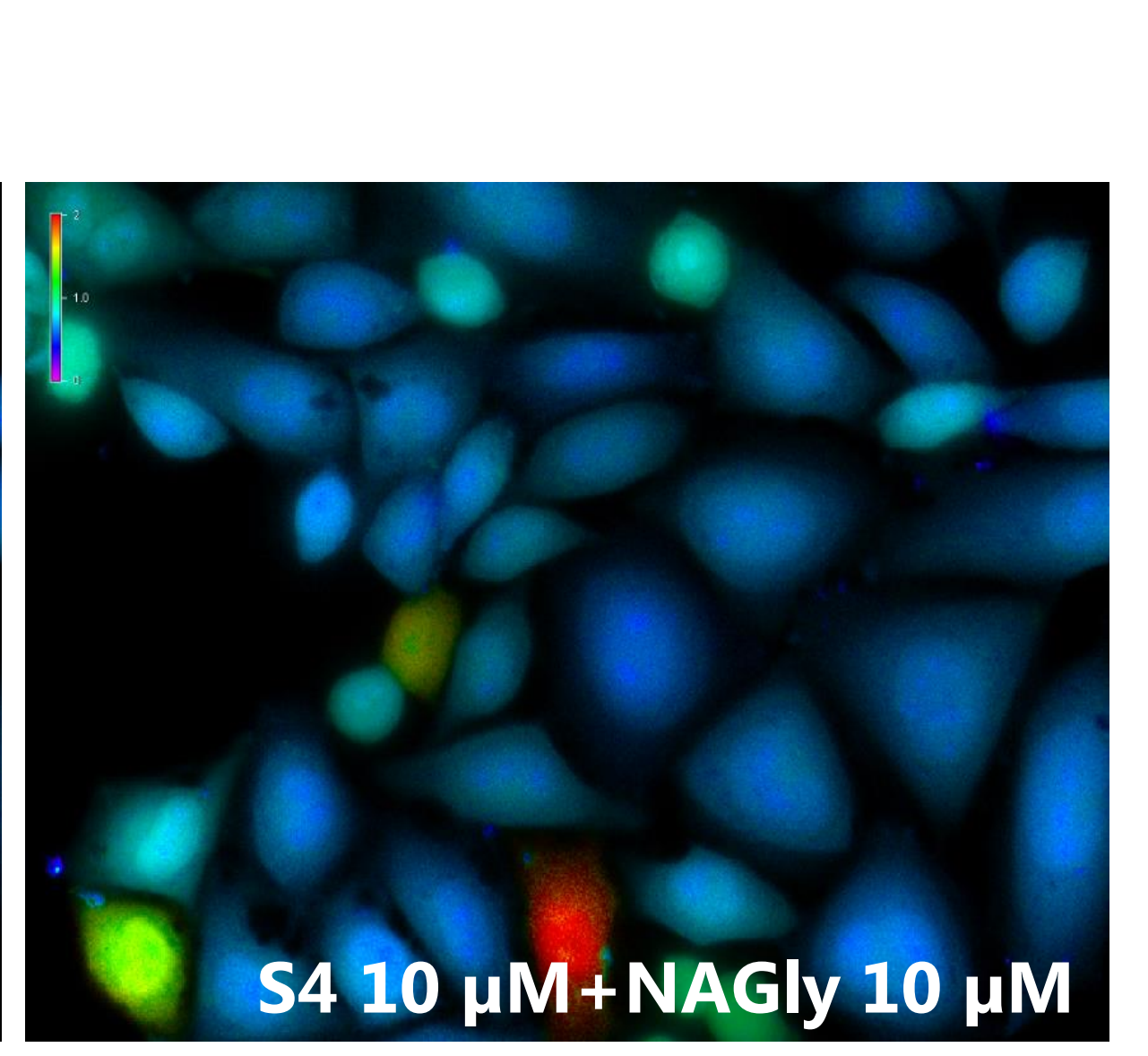

1B

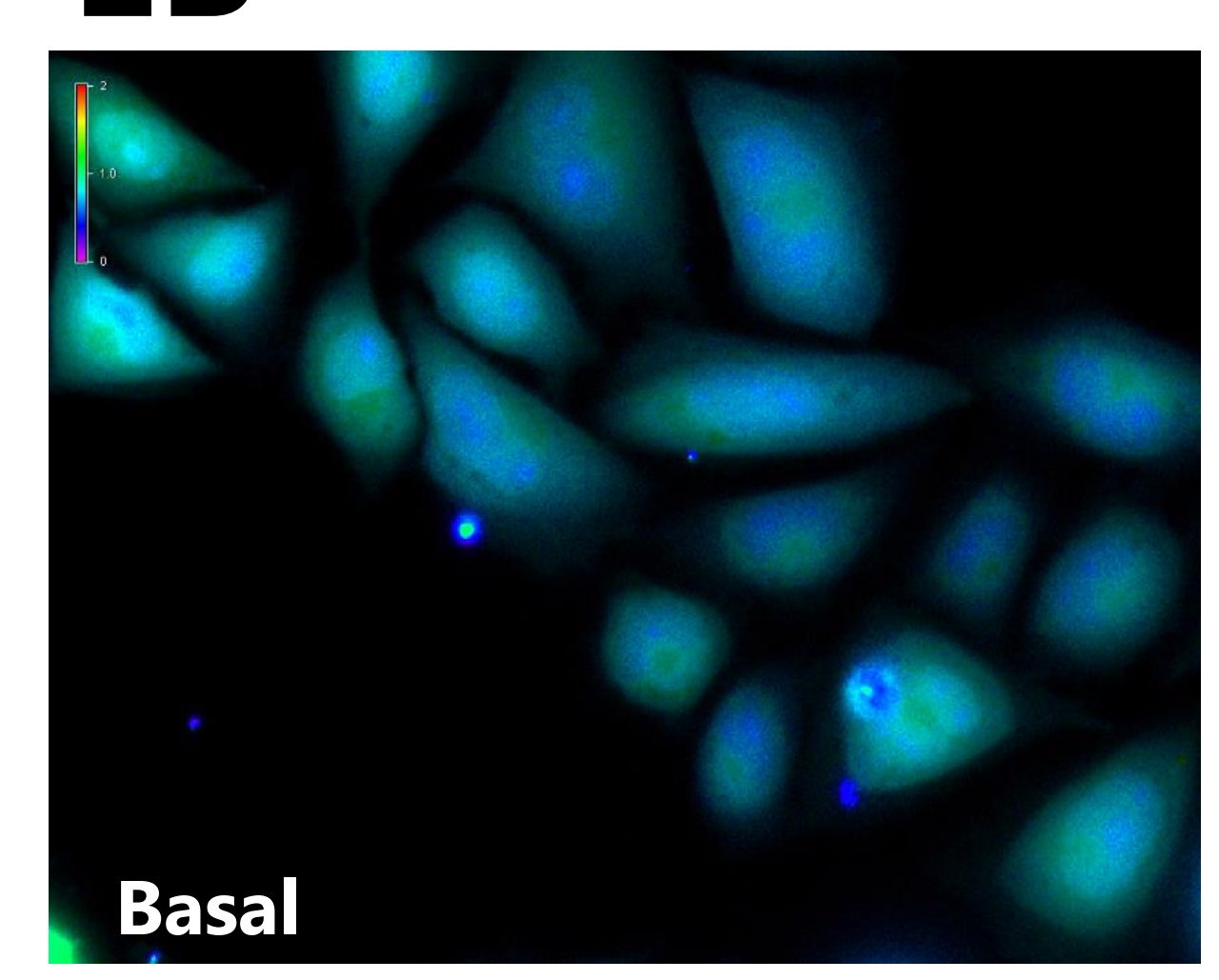

1D

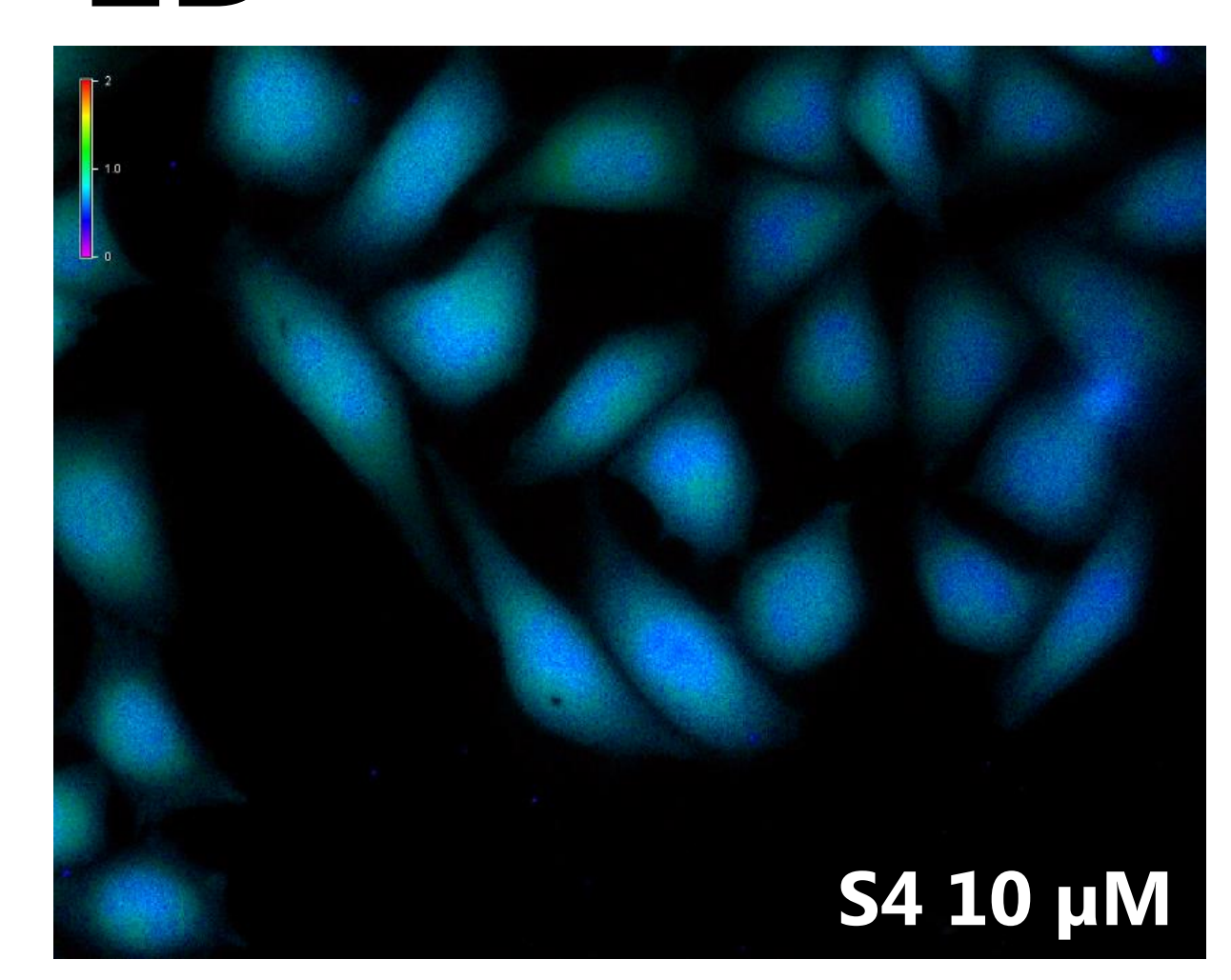

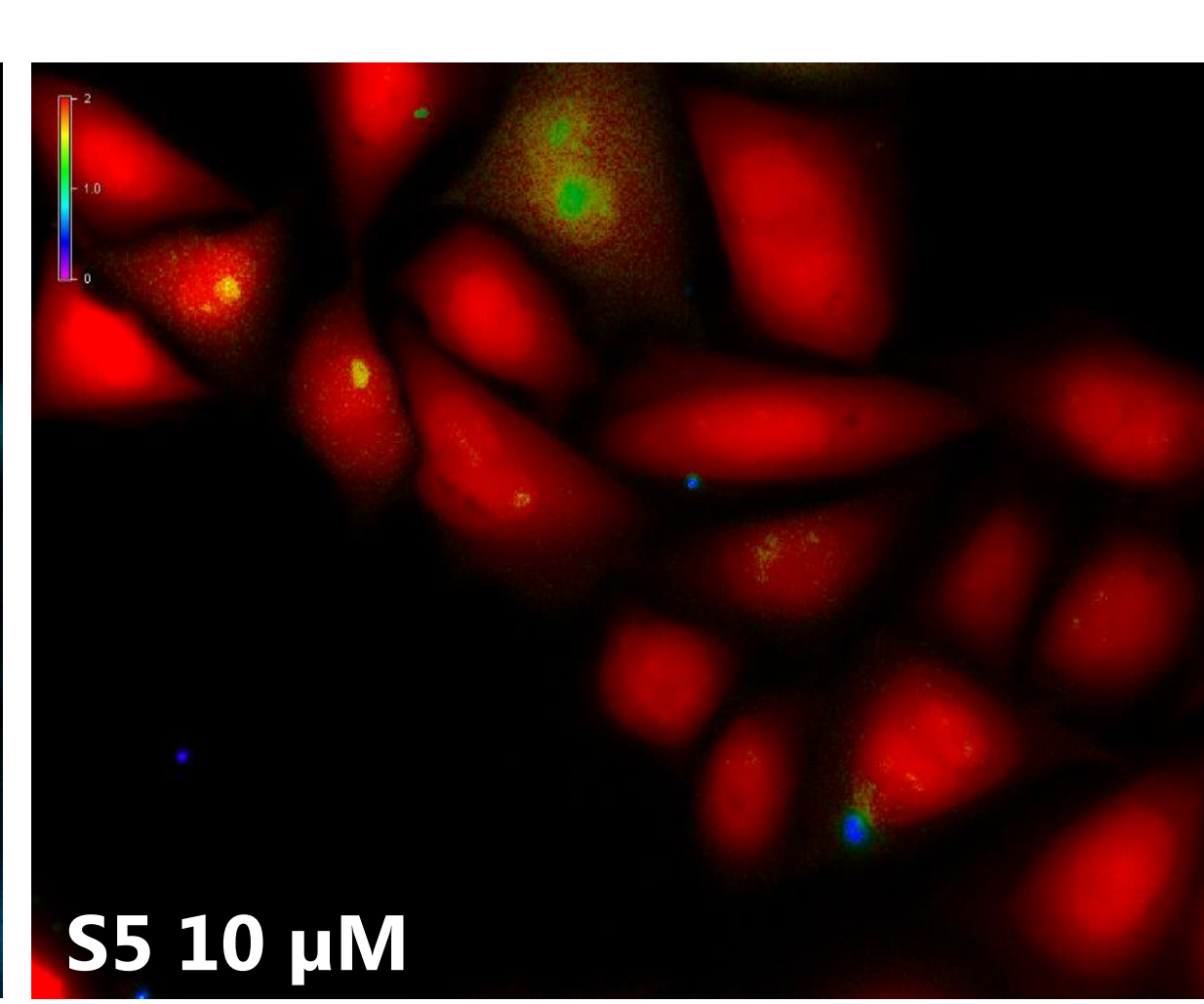

$5510 \mu \mathrm{M}$

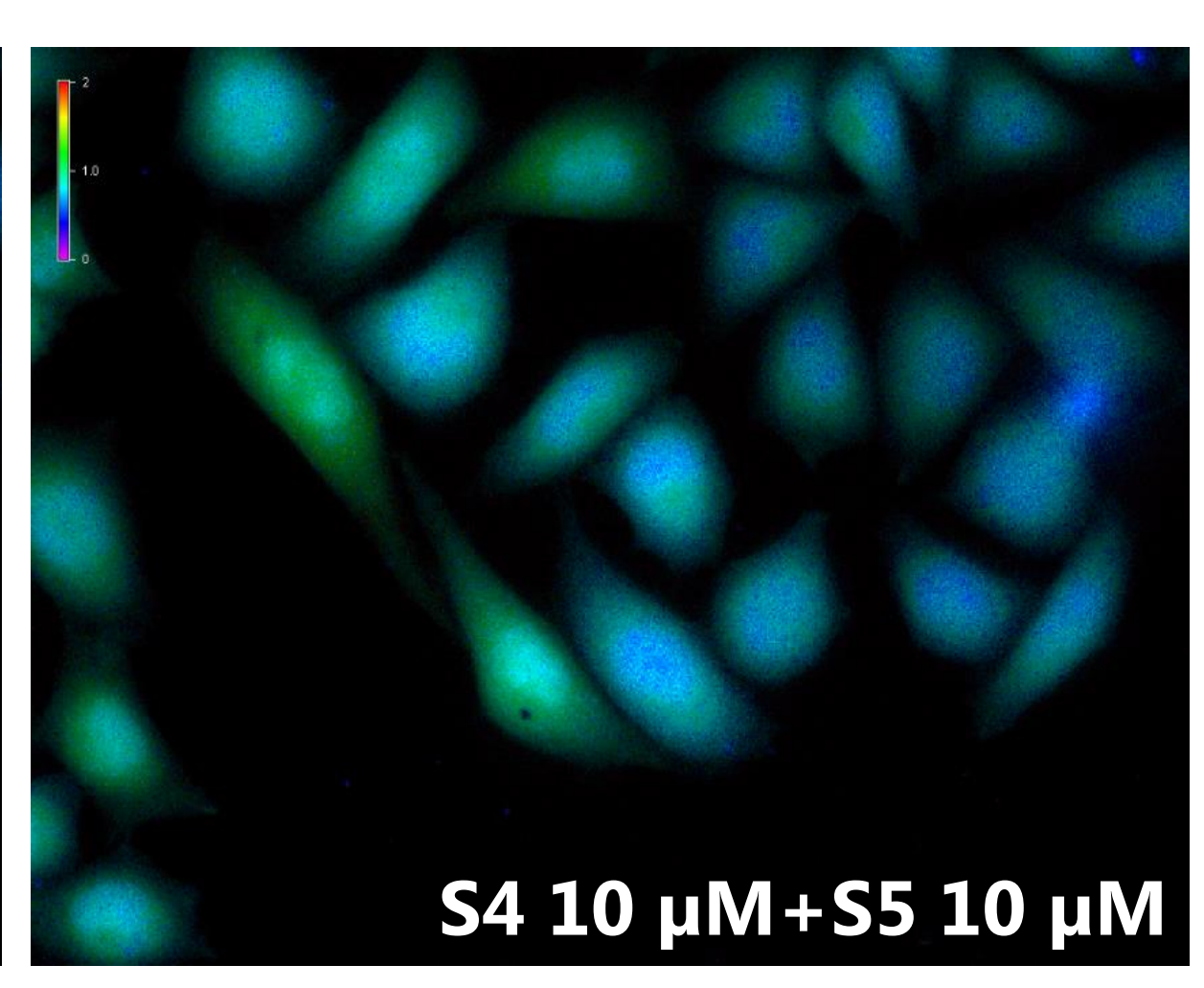

Figure 1. A,B: Representative micrograph of intracellular calcium mobilization in CHO-K1/GPR18 cells before and after exposure to NAGly 10 $\mu \mathrm{M}$ (A), and S5 $10 \mu \mathrm{M}$ (B). C,D: GPR18 antagonism of S4 $10 \mu \mathrm{M}$ of NAGly $10 \mu \mathrm{M}$ (C), and S5 $10 \mu \mathrm{M}$ (D).

Figure 2. Docking of S5 (in violet) complexed with GPR18* (active state) (A), and S4 (in green) complexed with GPR18 (inactive state) (B). Relevant residues are higlighted in magenta in each bundle.
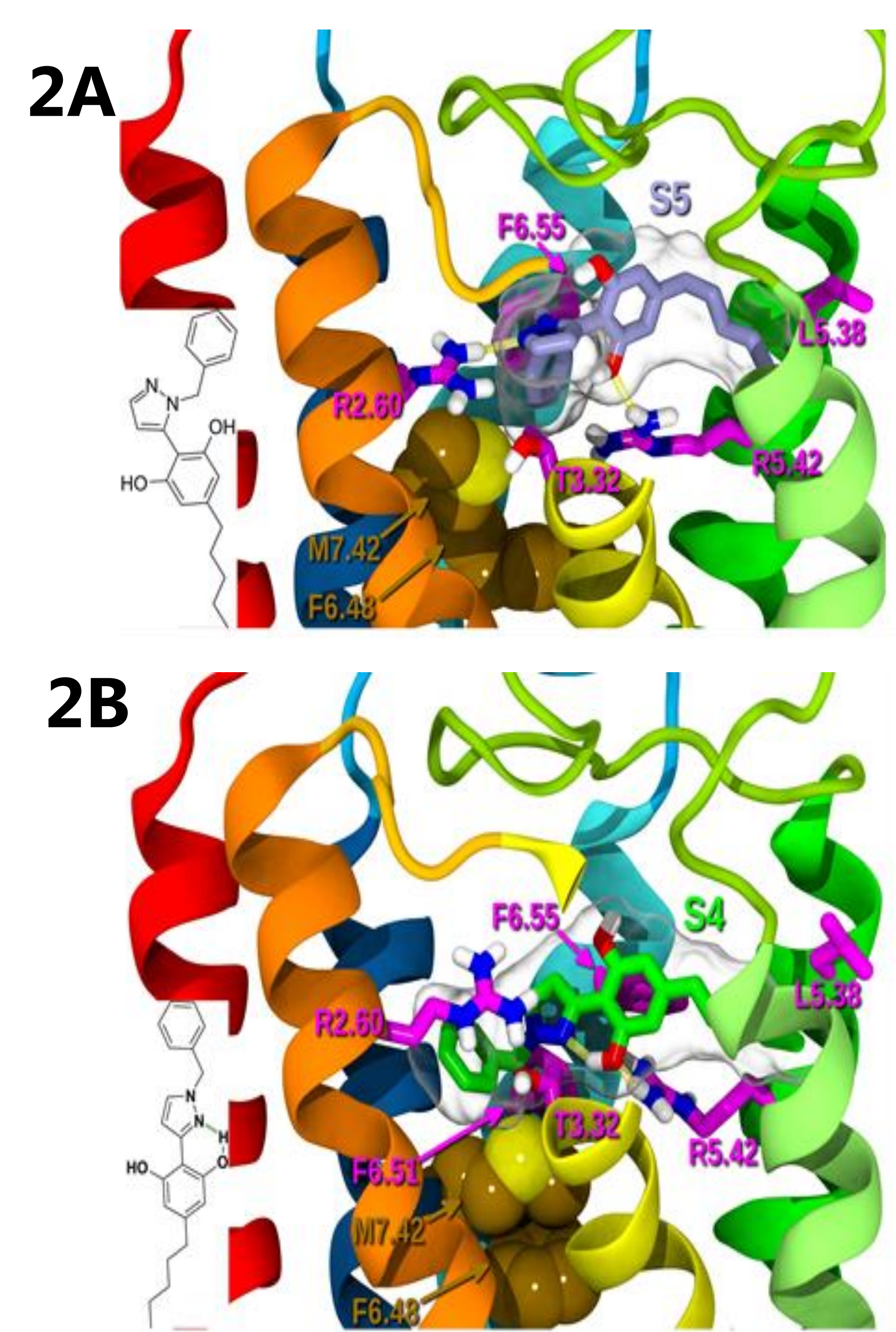

\section{CONCLUSIONS}

GPR18 is a very promising pharmacological target. However, the lack of potent and selective ligands for this orphan GPCR has limited its potential. As shown in the present work, we have generated a new set of synthetic compounds with a cannabidiol-like scaffold and a robust activity over GPR18. Two of most relevant compounds from this family, S4 and S5 are here represented. Docking studies in either the active or inactive states of GPR18 revealed the main sites of interaction of the ligands. Further in vitro and in vivo studies are needed to fully determine their signaling mechanisms and their potential as novel anti-inflammatory agents.

\section{IQM,}

